\title{
Effects of Lacosamide in Rats with Lipopolysaccharide Induced Hepatic Pathology
}

\author{
回 Ozlem Ozmen ${ }^{1 \star}$, Volkan Ipek $^{1}$
}

1 Burdur Mehmet Akif Ersoy University, Faculty of Veterinary Medicine, Department of Pathology, Burdur, Turkey

Received 2019-12-27 Accepted 2020-05-21

\begin{abstract}
Bacterial lipopolysaccharides (LPS) generally increase the pathogenicity of the agent. This study aimed to examine the hepatic pathology and possible prophylactic effects of lacosamide (LCM) in a LPS-induced sepsis rat model. Overall, 24 1-year-old female Wistar Albino rats were divided into three groups: Group I (control), Group II (LPS group: $5 \mathrm{mg} / \mathrm{kg}$ LPS intraperitoneally, single dose), and Group III (LCM group: $40 \mathrm{mg} / \mathrm{kg}$ LCM intraperitoneally once daily for 3 days plus $5 \mathrm{mg} / \mathrm{kg}$ LPS $30 \mathrm{~min}$ after the last LCM treatment). Animals were euthanized 6 hours after LPS administration. Blood and liver samples collected during necropsy were analyzed biochemically, pathologically, and immunohistochemically. LPS caused a significant increase in serum aspartate aminotransferase, alanine aminotransferase, total bilirubin, direct bilirubin, indirect bilirubin, and alkaline phosphatase levels. Histopathological analysis revealed numerous neutrophil leucocyte infiltrations, slight hemorrhages in the liver, and degenerative or necrotic changes in hepatocytes. Increased expressions of malondialdehyde, C-reactive protein, heat shock protein-70, interleukin-1 $\beta$, and tumor necrosis factor- $\alpha$ were observed in the LPS administered group. LCM ameliorated the biochemical, histopathological, and immunohistochemical findings. The present study results revealed that LCM ameliorated the LPS-induced liver damage in the rat models as evidenced by the biochemical and pathological findings.
\end{abstract}

Keywords: immunohistochemistry, lacosamide, lipopolysaccharide (LPS), liver, pathology.

\section{Introduction}

Lipopolysaccharides (LPS) are large lipid- and polysaccharide-containing molecules found in the outer membrane of gram-negative bacteria. ${ }^{1}$ LPS in some bacteria play a pivotal role in the pathophysiology of sepsis. ${ }^{2}$ The intraperitoneal application of LPS is an experimental model for inducing systemic and hepatic inflammation in rodents. LPS may lead to dysfunction or failure of numerous organs, including the liver. ${ }^{3,4}$ Acute phase proteins (APPs) are increased after LPS administration. ${ }^{5}$ Endotoxemia is indicative of severity of the sepsis and the leading cause of death. ${ }^{6}$
Lacosamide (LCM) is a third-generation antiepileptic drug (AED) that was first approved in 2008 for use in adjunctive therapy for partial-onset seizures in adults. In 2014, LCM was approved by the FDA for use in monotherapy for partial-onset seizures. Unlike conventional sodium channel blockers, LCM stimulates the slow inactivation of sodium channels selectively. This action mechanism results in the stabilization of overexcitable neuronal membranes, inhibition of neuronal firing, and reduction of the long-term availability of channels without affecting the physiological function. ${ }^{7}$ LCM does not stimulate or inhibit the cytochrome $\mathrm{P} 450$ enzyme. It has low protein-binding ability $(<15 \%)$ due to its numerous destruction mechanisms and

* Corresponding author: Özlem ÖZMEN, Burdur Mehmet Akif Ersoy University, Faculty of Veterinary Medicine, 
does not interact with most clinically prescribed drugs. ${ }^{7,8}$ The entry of calcium $(\mathrm{Ca} 2+)$ into the cytoplasm is the most common signaling factor of cell damage in all cell types. The normal concentration of intracellular $\mathrm{Ca} 2+$ is typically lower than that of extracellular $\mathrm{Ca} 2+{ }^{9}, 10$ Therefore, excessive intracellular $\mathrm{Ca} 2+$ may activate degradative processes and cause toxic effects in cells. ${ }^{9,11}$ Similarly, sodium $(\mathrm{Na}+)$, which is the major cation in the extracellular space, can enter cells through various routes, especially during increased cell membrane permeability. ${ }^{12}$ A significant increase in $\mathrm{Na}+$ is characteristic of tissue injuries. ${ }^{13,14}$ The use of sodium channel blockers reduces both $\mathrm{Na}+$ entry and apoptotic neuronal death. ${ }^{14} \mathrm{~A}$ well-known fact is that $\mathrm{Na}+$ influx into the cell is accompanied by chloride ions $(\mathrm{Cl}-)$ and water that can lead to acute cell swelling and damage. ${ }^{15}$ The inhibition of $\mathrm{Na}+-\mathrm{H}+$ exchange attenuates ischemia-induced cell death. ${ }^{16,17}$ The primary focus of pharmaceutical research has been to discover effective therapeutic approaches that target voltage-gated $\mathrm{Na}+$ channels. ${ }^{18} \mathrm{LCM}$ facilitates slow inactivation of sodium channels. ${ }^{7,8}$

Ameliorative effect of LCM on sepsis induced polyneuropathy previously reported. ${ }^{19}$ But there is no knowledge about effect of LCM on LPS induced hepatic pathology. The objective of this study was to evaluate of the pathogenesis of sepsis and effect of LCM on LPS induced liver lesions. For this purpose, we evaluated the effects of LCM on liver via biochemical, histopathological and immunohistochemical findings in an in vivo rat model of sepsis.

\section{Materials and Methods}

\section{Animals}

The experiments were performed in accordance with the guidelines for animal research of the National Institutes of Health and were approved by the Committee on Animal Research at Burdur Mehmet Akif Ersoy University, Burdur, Turkey. Animals were maintained and used in accordance with the Animal Welfare Act and the Guide for the Care and Use of Laboratory Animals in the Experimental Animal Center of Burdur Mehmet Akif Ersoy University (approval number:308).

Before the experiment health status of all rats were controlled by a veterinarian who was responsible for the animals. Overall, 24 1-year-old female Wistar Albino rats were used and divided into three groups: Group I (control) (0.1 $\mathrm{ml} /$ oral and i.p. saline, single dose), $(\mathrm{n}=8)$, Group II (LPS group: $5 \mathrm{mg} / \mathrm{kg}$ LPS intraperitoneally, single dose; (i.p. lipopolysaccharide, $500 \mathrm{mg}$ flk, 048K4126, Sigma-Aldrich, USA), ${ }^{20}(\mathrm{n}=8)$, and Group III (LCM group: $40 \mathrm{mg} / \mathrm{kg}$ LCM intraperitoneally once daily for 3 days and $5 \mathrm{mg} / \mathrm{kg}$ LPS 30 min after the last LCM treatment; (Benvida $100 \mathrm{mg}$ tb/ Adeka Farmacy, Turkey $)^{19},(\mathrm{n}=8)$. LCM was dissolved in normal saline. Four rats weighing 350- $400 \mathrm{~g}$ were kept in a conventional cage, two cages used for each group, they placed in a temperature- $\left(21-22^{\circ} \mathrm{C}\right)$ and humidity $(60+$ $5 \%$ )-controlled room in which a 12:12 h light-dark cycle was maintained. All the rats were fed ad libitum a standard commercial chow diet (Korkuteli yem; Antalya, Turkey) and drinking water during the study. The rat numbers were minimalized and total numbers of the animals selected for reliable statistical analysis. Animals were euthanized 6 hours after LPS administration. During necropsy, blood and liver samples were collected for biochemical, pathological, and immunohistochemical analyses.

\section{Biochemical Analysis}

An autoanalyzer (Beckman Coulter AU680, California, USA) was used to determine the activities of aspartate aminotransferase (AST), alanine aminotransferase (ALT), total bilirubin (T. bil.), direct bilirubin (D. bil.), indirect bilirubin (I. bil.), albumin (ALB), and alkaline phosphatase (ALP) levels.

\section{Histopathological Examinations}

During necropsy, the collected liver samples were fixed in $10 \%$ neutral formalin. Samples were then processed routinely using an automatic tissue processor equipment (Leica ASP300S, Wetzlar, Germany) and embedded in paraffin wax. Tissue sections of 5- $\mu \mathrm{m}$ thickness were cut using a rotary microtome (Leica RM2155, Leica Microsystems, Wetzlar, Germany); they were then stained with hematoxylin-eosin (H\&E), placed on a mounting media and coverslipped, and examined under a light microscope. ${ }^{21}$

\section{Immunohistochemical Examinations}

For immunohistochemical analysis, liver samples were immunostained with antibodides raised against malondialdehyde (MDA) [Anti-Malondialdehyde antibody (ab6463)], C-reactive protein [Anti-C Reactive Protein antibody - Aminoterminal end (ab65842)], heat shock protein-70 (HSP-70) [Anti-Hsp70 antibody [5A5] (ab2787)], interleukin-1 $\beta$ (IL-1 $\beta$ ) [Anti-IL1 beta antibody (ab2105)], and tumor necrosis factor- $\alpha$ (TNF- $\alpha$ ) [Anti-TNF alpha antibody (ab6671)] using the streptavidin-biotin technique. All primary serums and secondary antibodies were purchased from Abcam (Cambridge, UK), and all primary antibodies used were 1/100 dilution. Primary antibodies were incubated for $60 \mathrm{~min}$, and immunohistochemistry was performed using biotinylated secondary antibody and streptavidinALP conjugate. Ready-to-use kits [EXPOSE Mouse and 
Rabbit Specific HRP/DAB Detection IHC kit (ab80436)] finding observed in CON and LCM group. were used as secondary antibodies and 3,3-diaminobenzidine as chromogen for 5 min. For negative controls, pri- Histopathological Findings mary antiserum step was omitted. Histopathological and Histopathological analysis revealed normal tissue archiimmunohistochemical examinations were performed on tecture in the control group. Microscopic examination of blinded samples. The percentage of immune-positive cells the LPS group revealed marked hyperemia, inflammatory for each marker was determined by counting 100 cells in reaction comprised of neutrophil leucocyte, and hemor10 different fields for every section under 40x rhages in livers. Additionally, degenerations in some cells objective magnification for all groups. ${ }^{22}$ Statistical were the other common findings in this group. However, analyses were performed on the results obtained from LCM treatment ameliorated the histopathological findings the image analyzer. Morphometric analyses were (Fig.1A-C).

performed using the Database Manual Cell Sens Life Science Imaging Software System (Olympus Co., Tokyo, Japan).

\section{Statistical Analysis}

One-way analysis of variance test was used to determine significant differences among the groups. The groups were compared using the non-parametric Kruskal-Wallis and Dunnett tests. Biochemical parameters that fit the normal distribution were obtained, and ANOVA, post-hoc LSD, Bonferroni, and Tukey tests were used to compare the groups. Differences among groups in the histopathological and immunohistochemical analyses were determined using the Bonferroni multiple comparison method. Calculations were made using the SPSS 20.0 program, and $\mathrm{p}<$ 0.05 was set as the level of significance.

\section{Results}

\section{Biochemical Findings}

LPS caused a significant increase in the serum AST, ALT, T. bil., D. bil., I. bil., and ALP levels. Serum ALB levels were not affected by LPS administration. The results of biochemical analysis are summarized in Table 1.

\begin{tabular}{|l|l|l|l|l|}
\hline & CON & LPS & LCM & P \\
\hline AST (IU/L) & $153.00 \pm 10.84$ & $588.00 \pm 322.02$ & $169.00 \pm 41.99$ & $\begin{array}{l}\text { Con-LPS }<0.01 \\
\text { Con-LCM (NS) } \\
\text { LPS-LCM (NS) }\end{array}$ \\
\hline ALT (IU/L) & $70.25 \pm 16.14$ & $178.75 \pm 54.63$ & $35.33 \pm 7.91$ & $\begin{array}{l}\text { Con-LPS }<0.01 \\
\text { Con-LCM (NS) } \\
\text { LPS-LCM (NS) }\end{array}$ \\
\hline T.bil (mg/dL) & $0.39 \pm 0.17$ & $0.71 \pm 0.28$ & $0.36 \pm 0.12$ & $\begin{array}{l}\text { Con-LPS }<0.05 \\
\text { Con-LCM (NS) } \\
\text { LPS-LCM <0.05 }\end{array}$ \\
\hline D.bil (mg/dL) & $0.020 \pm 0.002$ & $0.040 \pm 0.001$ & $0.015 \pm 0.002$ & $\begin{array}{l}\text { Con-LPS }<0.05 \\
\text { Con-LCM (NS) } \\
\text { LPS-LCM (NS) }\end{array}$ \\
\hline I.bil (mg/dL) & $0.37 \pm 0.17$ & $0.67 \pm 0.26$ & $0.35 \pm 0.12$ & $\begin{array}{l}\text { Con-LPS }<0.05 \\
\text { Con-LCM (NS) } \\
\text { LPS-LCM <0.05 }\end{array}$ \\
\hline ALB (g/dl) & $2.50 \pm 0.39$ & $2.55 \pm 0.37$ & $2.61 \pm 0.19$ & $\begin{array}{l}\text { Con-LPS (NS) } \\
\text { Con-LCM (NS) } \\
\text { LPS-LCM (NS) }\end{array}$ \\
\hline ALP (IU/L) & $183.12 \pm 140.59$ & $205.33 \pm 145.44$ & $45.79 \pm 18.69$ & $\begin{array}{l}\text { Con-LPS (NS) } \\
\text { Con-LCM (NS) } \\
\text { LPS-LCM (NS) }\end{array}$ \\
\hline
\end{tabular}

Table 1: Statistical analysis results of serum biochemical analysis and oxidative stress markers.

\section{Necropsy Findings}

At necropsy hyperemia at the hepatic vessel were the marked finding in LPS group. There was no pathological

Figure 1: Histopathological appearance of the livers. A) Normal histology in control group. H\&E; B) Inflammatory reaction (arrows) and hemorrhage (arrow head) in the LPS group. H\&E; C) decreased inflammatory reaction (arrow) in LCM-treated group. $\mathrm{H} \& \mathrm{E}$. Bar $=50 \mu \mathrm{m}$. MDA immunoreaction in the livers.

D) Negative immunoreaction in the control group. E) Increased immunoexpression (arrows) in hepatocytes in the LPS group.

F) Slight immunoexpression (arrow) in the LCM-treated group. CRP immunoreactions in the livers. G) Negative immunoreaction in the control group. H) Increased immunoexpression (arrows) in hepatocytes in the LPS group. I) No immunoexpres-sion in the LCM-treated group. Streptavidinbiotin peroxidase. Bars $=50 \mu \mathrm{m}$.

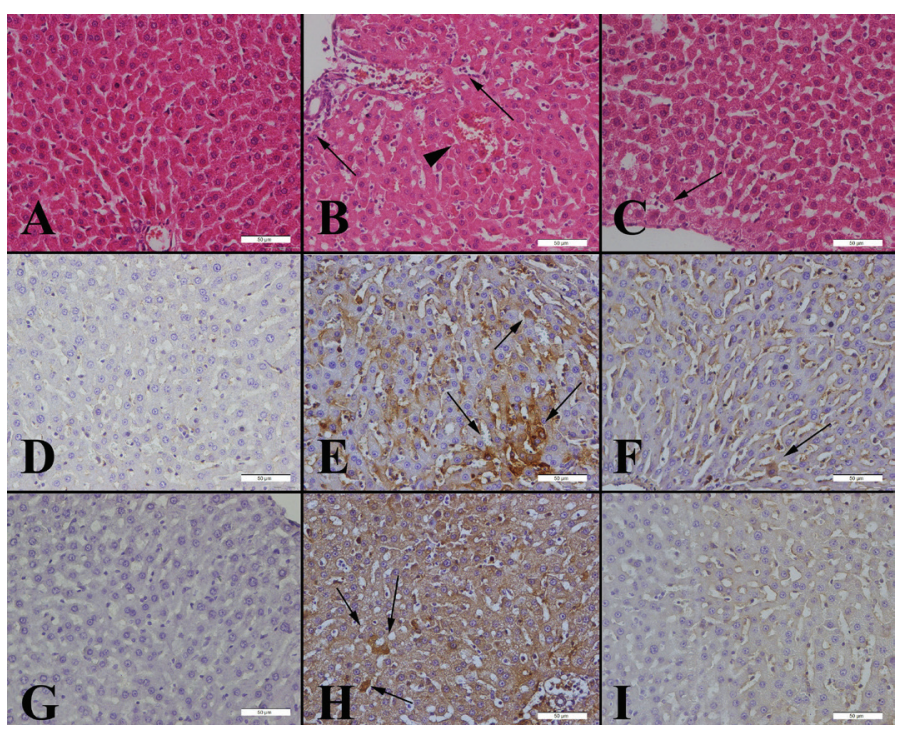

\section{Immunohistochemical Findings}

Immunohistochemical analyses revealed little or no expression of the investigated molecules in the control group. However, LPS caused an increase in the expressions of MDA, CRP, HSP-70, IL-1 $\beta$, and TNF- $\alpha$ in hepatocytes and sinusoidal endothelial cells intracytoplasmically. The most significantly expressed markers were IL-1 $\beta$, HSP-70, and TNF- $\alpha$, respectively. Notably, LCM had an ameliorative effect and caused a statistically significant decrease in the expression of all markers (Figs. 1D-I, 2), (Table 2). 


\begin{tabular}{|l|l|l|l|l|}
\hline Markers & Control & LPS & LCM & P value \\
\hline MDA & $0.50 \pm 0.37$ & $6.83 \pm 0.98$ & $1.33 \pm 0.51$ & $\begin{array}{l}\text { Con-LPS }<0.001 \\
\text { Con-LCM (NS) } \\
\text { LPS-LCM }<0.001\end{array}$ \\
\hline CRP & $1.25 \pm 0.36$ & $11.83 \pm 2.15$ & $2.07 \pm 0.36$ & $\begin{array}{l}\text { Con-LPS }<0.001 \\
\text { Con-LCM (NS) } \\
\text { LPS-LCM }<0.001\end{array}$ \\
\hline HSP-70 & $1.00 \pm 0.32$ & $16.16 \pm 1.10$ & $2.16 \pm 0.70$ & $\begin{array}{l}\text { Con-LPS }<0.001 \\
\text { Con-LCM (NS) } \\
\text { LPS-LCM }<0.001\end{array}$ \\
\hline IL1- $\beta$ & $0.50 \pm 0.26$ & $27.33 \pm 1.52$ & $2.16 \pm 0.70$ & $\begin{array}{l}\text { Con-LPS }<0.001 \\
\text { Con-LCM (NS) } \\
\text { LPS-LCM }<0.001\end{array}$ \\
\hline TNF- $\alpha$ & $1.85 \pm 0.50$ & $15.66 \pm 1.22$ & $2.50 \pm 0.42$ & $\begin{array}{l}\text { Con-LPS }<0.001 \\
\text { Con-LCM (NS) } \\
\text { LPS-LCM }<0.001\end{array}$ \\
\hline
\end{tabular}

Table 2: Statistical analysis of immunohistochemically positive cell numbers in the livers among the groups.

Figure 2: HSP-70 immunoreaction in the livers. A) Negative immunoreaction in the control group. B) Increased immunoexpression (arrows) in hepatocytes in the LPS group. C) Slight immunoexpression (arrows) in the LCM-treated group. IL-1 $\beta$ immunoreaction in the livers. D) No immunoreaction in hepatocytes in the control group. E) Increased immunoexpression (arrows) in hepatocytes in the LPS group. F) Negative immunoexpression in the LCM-treated group. TNF- $\alpha$ immunoreaction in the livers. G) Slight immunoreaction in hepatocytes (arrow) in the control group. H) Increased immunoexpression (arrows) in hepatocytes in the LPS group. I) Decreased immunoexpression (arrow) in the LCM-treated group. Streptavidin-biotin peroxidase. Bar $=50 \mu \mathrm{m}$.

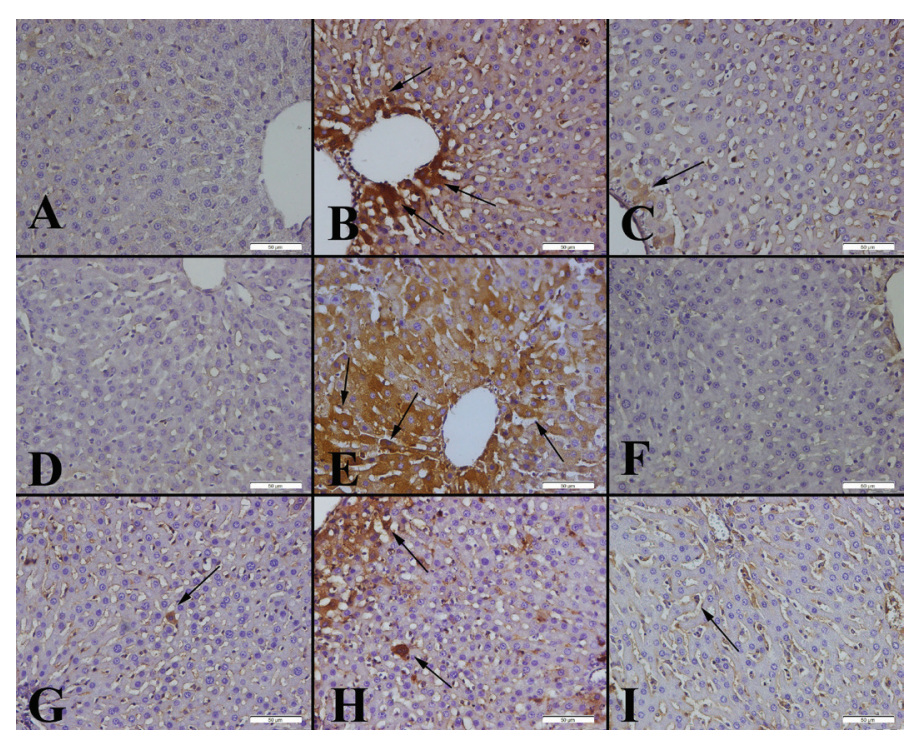

\section{Discussion}

This study revealed that LPS caused liver damage in rats and that the pathogenesis was associated with increased expression of IL-1 $\beta$, HSP-70, TNF- $\alpha$, CRP, and MDA. LCM can be a possible drug choice in the prevention of LPS-induced liver lesions.

LD50 dose of the LPS for rats previously reported as greater than $20 \mathrm{mg} / \mathrm{kg}$ in normal rats at 24 hours. ${ }^{23}$ The most preferred dose for single intraperitoneal injection of LPS is $5 \mathrm{mg} / \mathrm{kg}$ for rats. ${ }^{24-26}$ Dose selection were made based of the previous studies.

The induction of hepatic injury becomes evident because of the elevated levels of serum AST and ALT, which can be measured using standard clinical chemistry. Typically, when an inflammation-modifying substance needs to be tested, it is mandatory to analyze a control group simultaneously that only receives LPS and has no further intervention. ${ }^{4}$ Bacterial LPS, also known as endotoxin or lipoglycan, is the major component of the outer surface of gram-negative bacteria. ${ }^{27}$ Our study observed significant increases in the levels of serum ALT, AST, ALP, T. bil., D. bil., and I. bil. in the LPS group. However, LCM treatment attenuated the biochemical results.

LPS activates Toll-like receptor 4 and eventually nuclear factor-kappa B (NF- $\kappa \mathrm{B})$ mechanism followed by the release of inflammatory cytokines, such as TNF- $\alpha$, IL- $1 \alpha / \beta$, IL-6, IL-12, IL-18, and GM-CSF. ${ }^{4}$ Oxidative stress is also a well-known mechanism of LPS-induced hepatic injury which is supported by reactive oxygen species. ${ }^{28}$ A large proportion of proinflammatory mediators comprising cytokines are responsible for metabolic changes associated with cellular injury. ${ }^{29}$ Cytokines function as mediators of the immune and acute phase responses. TNF- $\alpha$, IL- $1 \beta$, and IL- 6 are the major mediators of acute phase response in humans. ${ }^{30}$ Additionally, IL-6 functions as an endogenous pyrogen that stimulates the immune system and, in conjunction with TNF- $\alpha$, can stimulate the synthesis of acute phase proteins, such as CRP from hepatocytes. ${ }^{31}$ The immunohistochemical examination of our study revealed substantially increased expression of MDA, CRP, HPS-70, IL- $1 \beta$, and TNF- $\alpha$. However, LCM was observed to be effective in reducing both inflammatory and oxidative damage markers. We believe that the most suitable markers to evaluate LPS-induced hepatic damage are IL-1 $\beta$, HSP-70, TNF- $\alpha$, CRP, and MDA.

Despite several studies have been focused on this subject, the mechanism of LPS-induced endotoxemia is still not completely clear. It has been suggested that oxygen-derived radicals are generated during endotoxic shock that induce tissue injury. Lipid peroxidation may then be initiated, inducing further tissue damage. ${ }^{28-32}$ Lipid peroxidation with unsaturated lipids generates a wide variety of oxidation products. Notably, the primary products of lipid peroxidation are lipid hydroperoxides. The secondary and most mutagenic product formed during lipid peroxidation 
is MDA. ${ }^{33} \mathrm{~A}$ majority of the toxic effects of LPS are mediated by proinflammatory cytokines, such as TNF- $\alpha$, IL$1 \alpha$, and IL- $1 \beta$, that are produced by monocytes and macrophages. ${ }^{34}$ TNF- $\alpha$ reportedly plays a central role in the pathology of LPS-induced lethality. ${ }^{3}$ Furthermore, CRP is an acute phase reactant that is synthesized and released by various cells, including hepatocytes in response to microbial infection, tissue injury, and immunomodulatory stimuli. ${ }^{35}$ Additionally, HSPs are a group of stress proteins that are actively synthesized when macrophages are exposed to bacterial toxins. ${ }^{36}$ HSPs are present in almost all eukaryotic cells, including hepatocytes, and are transiently overexpressed when cells are exposed to heat shock. ${ }^{37}$ HSP-70 is an abundant and well-conserved, stress-inducible protein that plays a vital role in the cellular stress response and enables organisms to survive multiple environmental stresses. It is constitutively expressed and is essential in the normal functioning of cells. ${ }^{38}$ Notably, when cells are exposed to a stressor, the rapid increase in HSP-70 levels reportedly protects cells from the harmful effects of the stressor. ${ }^{39}$ The protective effect of HSP-70 has been demonstrated in a variety of cells, tissues, and organs. ${ }^{39,40}$ In this study, we examined LPS-induced liver toxicity and the effect of LCM on acute sepsis through biochemical, histopathological, and immunohistochemical methods. We identified that MDA, CRP, HSP-70, IL-1 $\beta$, and TNF- $\alpha$ play important roles in LPS-induced hepatic pathology. Liver histopathology revealed that hyperemia, hemorrhage, inflammatory reaction mainly comprising neutrophil accumulation, and necrotic changes in hepatocytes in the LPS group indicated classic signs of hepatic damage. Increased immunoexpression of the markers was indicative of lipid peroxidation and acute phase reaction, which are critical factors of LPS-

induced hepatic damage.

Few reports have suggested an increase in enzymes and toxicity in the liver following LCM treatment ${ }^{41-43}$ with hepatic impairment considered to be a severe side effect of LCM. ${ }^{44}$ However, in all these cases, LCM was administered for a longer term with multiple doses. Conversely, our results suggested that three doses of LCM can produce ameliorative effects in liver damage. Unfortunately, the mechanism of this effect is elusive. Nonetheless, the possibility of an interaction of LCM-a sodium channel inhibitor-with the epithelial sodium channels of hepatocytes via an un-known mechanism is suggested. Notably, in rat and mice, the brain and liver intestine sodium channels (BLINaC) are predominantly expressed in the brain, liver, and intestine. ${ }^{45}$ However, the functions of these channels remain unknown. ${ }^{46}$ Therefore, we suggest that LCM affects these channels to prevent sodium influx in hepatocytes that can cause degenerative changes and decrease inflammatory and free radical injury via an unknown mechanism.

In our study, we used only $40 \mathrm{mg} / \mathrm{kg}$ for three days followed by one dose of LPS (5 mg/kg) and obtained unexpected results because the LCM improved the liver condi-tion. Chronic nature of epilepsy necessitates lifelong use of AEDs. Generally, epilepsy cannot be controlled with a single AED in more than $30 \%$ of patients; therefore, multiple AEDs are needed. ${ }^{7} \mathrm{New}$ AEDs, such as levetiracetam and LCM, are more suitable options for patients with hepat-ic impairment compared with the older $\mathrm{AEDs}^{46-47}$ because these drugs are less likely to exacerbate liver damage. Moreover, these drugs show low or no serum protein-binding capacity, ${ }^{47}$ lower drug-to-drug interaction, and minimal toxicity risk. $^{5,48}$ LCM is metabolized by the CYP450, 2C19 system, but its metabolites are inactive. Its proteinbinding capacity is lower than 15\%, and approximately $40 \%$ of it is excreted in the urine. LCM is also a safe choice because of its linear pharmacokinetics. ${ }^{46}$ Although the long-term usage of LCM may produce liver damage, we observed that three doses of LCM did not induce liver injury but surpris-ingly ameliorated serum biochemical levels of liver enzyme and improved histopathological and immunohistochemical findings. We also reported that ameliorative effects of LCM on LPS induced neuro inflammation and urogenital system damage by using related organs of these study rats recently. ${ }^{49,50}$

Therefore, to conclude, three doses of LCM can prevent LPS-induced acute liver damage by suppressing both inflammatory and oxidative injuries through an unknown mechanism. However, further studies are warranted to understand this mechanism entirely. However, the possibility of exacerbation of liver damage must be considered when using this drug for a longer duration.

Declaration of interest: The authors report no conflicts of interest. The authors alone are responsible for the content and writing of this paper.

\section{References}

1. Wolff A. Uber Grundgesetze der Immunitat. Bakteriol. 1904;37:390-7.

2. Raetz CR. Bacterial endotoxins: extraordinary lipids that activate eucaryotic signal transduction. J Bacteri-ol. 1993 Sep;175(18):5745-53.

3. Nowak M, Gaines G, Rosenberg J, Minter R, Bahjat F Rectenwald J, et. al. LPS-induced liver injury in d -galactosamine-sensitized mice requires secreted TNF-and the TNF-p55 receptor. Am J Physiol - Regul Inter-grative Comp Physiol. 2000; May; 278(5):R1202-9.

4. Hamesch K, Borkham-Kamphorst E, Strnad P, Wei- 
skirchen R. Lipopolysaccharide-induced inflammatory liver injury in mice. Lab Anim. 2015 Apr 2;49(1-suppl):37-46.

5. Haziot A, Lin XY, Zhang F, Goyert SM. Cutting edge: The induction of acute phase proteins by lipopolysaccharide uses a novel pathway that is CD14-independent. J Immunol. 1998 March 15;160 (6): 2570-2.

6. Exley AR, Leese T, Holliday MP, Swann RA, Cohen J. Endotoxaemia and serum tumour necrosis factor as prognostic markers in severe acute pancreatitis. Gut. 1992 Aug 1;33(8):1126-8.

7. Cawello W. Clinical pharmacokinetic and pharmacodynamic profile of lacosamide. Clin Pharmacokinet. 2015 Sep 9;54(9):901-14.

8. de Biase S, Gigli GL, Valente M, Merlino G. Lacosamide for the treatment of epilepsy. Expert Opin Drug Metab Toxicol. 2014 Mar 30;10(3):459-68.

9. Clapham DE. Calcium signaling. Cell. 1995 Jan 27;80(2):259-68.

10. Dong Z, Saikumar P, Weinberg JM, Venkatachalam MA. Calcium in cell injury and death. Annu Rev Pathol Mech Dis. 2006 Feb;1(1):405-34.

11. Zipfel GJ, Babcock DJ, Lee J-M, Choi DW. Neuronal apoptosis after CNS injury: The roles of glutamate and calcium. J Neurotrauma. 2000 Oct;17(10):857-69.

12. Nikolaeva MA, Mukherjee B, Stys PK. Na+-dependent sources of intra-axonal $\mathrm{Ca} 2+$ release in rat optic nerve during in vitro chemical ischemia. J Neurosci. 2005 Oct 26;25(43):9960-7.

13. Ballard-Croft C, Carlson D, Maass DL, Horton JW. Burn trauma alters calcium transporter protein expression in the heart. J Appl Physiol. 2004 Oct;97(4):14706.

14. Banasiak K., Burenkova O, Haddad G. Activation of voltage-sensitive sodium channels during oxygen deprivation leads to apoptotic neuronal death. Neuroscience. 2004 Jan;126(1):31-44.

15. Choi DW. Calcium: still center-stage in hypoxic-ischemic neuronal death. Trends Neurosci. 1995 Feb;18(2):58-60.

16. Vornov JJ, Thomas AG, Jo D. Protective effects of extracellular acidosis and blockade of sodium/hydrogen ion exchange during recovery from metabolic inhibition in neuronal tissue culture. J Neurochem. 1996 Dec;67(6):2379-89.

17. Mentzer RM, Lasley RD, Jessel A, Karmazyn M. Intracellular sodium hydrogen exchange inhibition and clinical myocardial protection. Ann Thorac Surg. 2003 Feb;75(2):S700-8.

18. Baptiste DC, Fehlings MG. Update on the treatment of spinal cord injury. In: Progress in brain research. 2007. p. 217-33.

19. Solmaz V, Aksoy D, Yllmaz M, Eser E, Erbas O. Demonstration of ameliorative effect of lacosamide: in a ratmodel of sepsis-induced critical illness polyneuropathy. Neurol Res. 2015 Sep;37 (9):797-802.

20. Samuvel D, Shunmugavel A, Singh A, Singh I, Khan M, S-Nitrosoglutathione ameliorates acute renal dysfunction in a rat model of lipopolysaccharide-induced sepsis. J Pharm Pharmacol. 2016 Oct; 68 (10):1310-9.

21. Luna G. Manual of Histologic Staining Methods of the Armed Forces Institute . of Pathology. 3rd editio. New York: McGraw Hill Book Co; 1968. 32-34 p.

22. Haligur M, Topsakal S, Ozmen O. Early degenerative effects of Diabetes mellitus on pancreas, liver and kidney in rats; An immunohistochemical study. Exp Diabetes Res. 2012; Article ID 120645, 10 pages, doi:10.1155/2012/120645.

23. Harry D, Anand R, Holt S, Davies S, Marley R, Fernando $\mathrm{B}$, et al. Increased sensitivity to endotoxemia in the bile duct-ligated cirrhotic rat. Hepatology. 1999 Nov;30(5):1198-205.

24. Li G, Liu Y, Tzeng N, Cui G, Block ML, Wilson B, et al. Protective effect of dextromethorphan against endotoxic shock in mice. Biochem Pharmacol. 2005 Jan 15;69(2):233-40.

25. Qin L, Wu X, Block ML, Liu Y, Breese GR, Hong J-S, et al. Systemic LPS causes chronic neuroinflammation and progressive neurodegeneration. Glia. 2007 Apr 1;55(5):453-62.

26. Bossù $\mathrm{P}$, Cutuli D, Palladino I, Caporali $\mathrm{P}$, Angelucci $\mathrm{F}$, Laricchiuta D, et al. A single intraperitoneal injection of endotoxin in rats induces long-lasting modifications in behavior and brain protein levels of TNF- $\alpha$ and IL18. J Neuroinflammation. 2012 Dec 29;9(1):671.

27. Caroff M, Karibian D. Structure of bacterial lipopolysaccharides. Carbohydr Res. 2003 Nov 14;338(23):2431-47.

28. Ajuwon OR, Oguntibeju OO, Marnewick JL. Amelioration of lipopolysaccharide-induced liver injury by aqueous rooibos (Aspalathus linearis) extract via inhibition of pro-inflammatory cytokines and oxidative stress. BMC Complement Altern Med. 2014 Dec 13;14(1):392.

29. Hill AG, Hill GL. Metabolic response to severe injury. Br J Surg. 1998 Jul;85(7):884-90.

30. Leung KL, Lai PB, Ho RL, Meng WC, Yiu RY, Lee JF, et al. Systemic cytokine response after laparoscopic-assisted resection of rectosigmoid carcinoma: A prospective randomized trial. Ann Surg. 2000 Apr;231(4):506-11.

31. Wortel CH, van Deventer SJ, Aarden LA, Lygidakis NJ, 
Büller HR, Hoek FJ, et al. Interleukin-6 mediates host defense responses induced by abdominal surgery. Surgery. 1993 Sep;114(3):564-70.

32. Requintina PJ, Oxenkrug GF. Differential effects of lipopolysaccharide on lipid peroxidation in F344N, SHR rats and $\mathrm{BALB} / \mathrm{c}$ mice, and protection of melatonin and NAS against its toxicity. Ann N Y Acad Sci. 2003 May;993:325-33; discussion 345-9.

33. Esterbauer H, Schaur RJ, Zollner H. Chemistry and biochemistry of 4-hydroxynonenal, malonaldehyde and related aldehydes. Free Radic Biol Med. 1991;11(1):81-128.

34. Lynn WA, Cohen J. Adjunctive therapy for septic shock: a review of experimental approaches. Clin Infect Dis. 1995 Jan;20(1):143-58.

35. Venugopal SK, Devaraj S, Jialal I. Macrophage Conditioned Medium Induces the Expression of C-Reactive Protein in Human Aortic Endothelial Cells. Am J Pathol. 2005 Apr;166(4):1265-71.

36. Teshima S, Rokutan K, Takahashi M, Nikawa T, Kishi $\mathrm{K}$. Induction of heat shock proteins and their possible roles in macrophages during activation by macrophage colony-stimulating factor. Biochem J. $1996 \mathrm{Apr}$ 15;315 ( Pt 2(Pt 2):497-504.

37. Rai R, Richardson C, Flecknell P, Robertson H, Burt A, Manas DM. Study of Apoptosis and Heat Shock Protein (HSP) Expression in Hepatocytes Following Radiofrequency Ablation (RFA). J Surg Res. 2005 Nov;129(1):147-51.

38. Hartman D, Gething MJ. Normal protein folding machinery. EXS. 1996;77:3-24.

39. Wang J, Wei Y, Li X, Cao H, Xu M, Dai J. The identification of heat shock protein genes in goldfish (Carassius auratus) and their expression in a complex environment in Gaobeidian Lake, Beijing, China. Comp Biochem Physiol Part C Toxicol Pharmacol. 2007 Apr;145(3):350-62.

40. Padmini E, Usha Rani M. Impact of seasonal variation on HSP70 expression quantitated in stressed fish hepatocytes. Comp Biochem Physiol Part B Biochem Mol Biol. 2008 Nov;151(3):278-85.

41. Ben-Menachem E, Biton V, Jatuzis D, Abou-Khalil B, Doty P, Rudd GD. Efficacy and Safety of Oral Lacosamide as Adjunctive Therapy in Adults with Partial-Onset Seizures. Epilepsia. 2007 Jul;48(7):1308-17.

42. Gutiérrez-Grobe Y, Bahena-Gonzalez JA, Herrera-Gomar M, Mendoza-Diaz P, García-López S, GonzálezChon O. Acute Liver Failure Associated with Levetiracetam and Lacosamide Combination Treatment for Unspecified Epileptic Disorder. Case Rep Emerg Med. 2013;2013:1-3.
43. Sunwoo J-S, Byun J-I, Lee SK. A case of lacosamide-induced hepatotoxicity. Int J Clin Pharmacol Ther. 2015 Jun 1;53(06):471-3.

44. Zaccara G, Perucca P, Loiacono G, Giovannelli F, Verrotti A. The adverse event profile of lacosamide: A systematic review and meta-analysis of randomized controlled trials. Epilepsia. 2013 Jan;54(1):66-74.

45. Wiemuth D, Gründer S. A single amino acid tunes $\mathrm{Ca} 2+$ inhibition of brain liver intestine $\mathrm{Na}+$ channel (BLINaC). J Biol Chem. 2010 Oct 1;285(40):30404-10.

46. Asconapé JJ. Use of antiepileptic drugs in hepatic and renal disease. In: Handbook of clinical neurology. 2014. p. 417-32.

47. Alvarez V, Rossetti AO. Monotherapy or Polytherapy for First-Line Treatment of SE? J Clin Neurophysiol. 2016 Feb;33(1):14-7.

48. Vidaurre J, Gedela S, Yarosz S. Antiepileptic Drugs and Liver Disease. Pediatr Neurol. 2017 Dec;77:23-36.

49. Savran M, Ozmen O, Erzurumlu Y, Savas HB, Asci S, Kaynak M. The impact of prophylactic lacosamide on LPS-Induced neuroinflammation in aged rats. Inflammation. 2019 Oct; 42(5): 19, 1913-25.

50. Günyeli,I, Saygın M, Ozmen O. Overall systematic approach to sepsis damages on urogenital tissues: protective power of lacosamide. Arch Gynecol Obstet. 2019 Oct; 300(4): 941-55. 